\title{
FORMATION OF PHYSICAL READINESS IN STUDENTS FOR SURVIVAL IN EXTREME SITUATIONS
}

\author{
Vesela Stoycheva \\ University of Architecture, Civil Engineering and Geodesy (Bulgaria)
}

\begin{abstract}
The problem of student survival in extreme situations is very relevant. The future professional activities of students are connected with actions in various potential extreme situations. It is necessary in the process of training at the university in students to form sufficient readiness for adequate actions in diverse extreme scenarios. On the basis of theoretical analysis of various concepts of extreme situations, it is defined as "a complex of environmental conditions requiring certain actions for a certain period of time". The main factors of the situation are danger and difficulty, and their integral functions are risk and effort, respectively. Situations are external and internal. Physical preparedness is made up of general and special physical qualities determining certain actions in accordance with the demands of extreme situations. The aim of the study is to form physical readiness in students for survival in extreme situations by applying a specialized impact methodology. The formation of physical readiness in students takes place in the process of regular classes in physical education and sport. Certain exercises are included in the individual classes, which have a positive influence on the formation of physical readiness for actions in extreme situations. In summarizing the variational and comparative analysis of the results of the study, it was found that the applied methods of influence in the process of conducting regular classes of students of physical education and sports has positively affected the physical readiness of young people in the experimental group.

Keywords: healing; physical preparedness; extreme situations
\end{abstract}

\section{Introduction}

The modern dynamic way of life has a negative impact on people and their physical readiness to overcome situations of varying degrees of extremity and survival. The demands on mental resilience are increased and physical activity is limited. Limited physical activity can affect negatively all vital organs and systems of the body. The professional activity of future architects, civil engineers and surveyors is largely related to overcoming various extreme situations. 
Extreme situations are seen as "a set of environmental conditions requiring active action over a period of time" (Kaykov 1988). Situations are external and internal. The impact factors of individual environments form certain conditions. The complex of these conditions forms a specific situation that requires a specific adaptation to the environment and specific actions. When the demands of the situation increase, adaptation is accelerated and actions are intensified. This situation is defined as extreme. The key factors of the extreme situation are danger and difficulty, and their integral functions are risk and effort, respectively. The degree of danger and difficulty determines the extremality of the situation.

Extreme situations, where the degree of danger is high, require active actions related to the preservation of life and survival. D. Kaykov defines survival as "a system of purposeful actions in extreme situations to preserve the life of the individual and human communities" (Kaykov 2004, 59). Survival is considered in different situations and conditions - in disaster situations (Alexiev 2004), in crisis situations (Marinov 2015), in combat conditions (Madansky 2013), etc. The effectiveness of survival actions in these situations is determined by the adequacy of the formed survival preparedness.

Extreme survival readiness is made up of four structures - mental, physical, technical and tactical preparedness, which are interrelated (Kaykov 2004). One of the main structures of extreme readiness is physical preparation. Physical readiness is a complex phenomenon that reflects the immediate preparedness of students to perform certain actions in various extreme situations.

Mental, technical and tactical readiness are realized in practice through physical readiness. T. Marinov considers physical readiness as "a complex phenomenon that reflects the immediate preparedness of a person to perform certain actions in various crisis situations" (Marinov 2015, 59). P. Geshev defines physical readiness as "the specific physical state of a person and is characterized by a certain degree of physical development, the functional state of the organism, a certain level of motor preparedness" (Geshev 2014, 70).

Physical readiness is made up of the basic physical qualities - speed, muscular strength, flexibility and agility, as well as special qualities - speed and strength endurance, etc. All physical qualities are in unity and are realized in actions depending on the nature of situations. This readiness is known as situational physical readiness. In the process of overcoming various situations, a sustainable physical readiness is gradually formed, which is realized in practice only through situational readiness.

The formation of physical readiness for survival in extreme situations in students is most appropriately conducted in physical education and sport classes. There are opportunities to enrich the content of the classes with reliable means and methods of impact. I. Stavreva proves the possibility of adapting the physical training of students of the Mining and Geological University "St. Ivan Rilski" - Sofia, to the requirements of their future professional activity (Stavreva 2015). At the University 
of Architecture, Civil Engineering and Geodesy (UACEG) on the basis of scientific researches was developed a methodology for specialized physical training of students for survival in extreme situations (Stoycheva 2019), formation of physical readiness for action in difficult situations (Stoycheva \& Kaykov 2018).

\section{Aim}

On the basis of theoretical analysis, the hypothesis is derived that the formation of adequate physical readiness in students for survival in extreme situations can be implemented through the application of specialized impact methodology in physical education and sports classes. The aim of the study is to form physical readiness in students for survival in extreme situations by applying a specialized impact methodology.

In order to achieve the goal the following tasks are solved:

1. Development of the theoretical foundations of the research problem.

2. Creation of specialized methodology of influence in students for formation of physical readiness for survival in extreme situations.

3. Experimentation of the methodology in physical education and sport classes.

4. Analyzing the research results, optimizing and implementing the specialized methodology.

The subject of the study is the effectiveness of the specialized methodology.

The object of the study were 82 students of UASG aged $18-23$ years divided into two groups - experimental (35 students), to which the impact methods were applied, and control group (47 students), to which no impact was applied. Both groups participated regularly in physical education and sport classes.

\section{Methodology}

In order to solve the tasks, achieve the goal and prove the hypothesis, a complex methodology of literature research, pedagogical observation, discussion, and a constitutive and transformative pedagogical experiment was applied. Two measurements of physical indicators were conducted at the beginning and at the end of the study. Six significant physical qualities that make up the structure of physical readiness were measured with defined tests: 1 . Speed with the Run $30 \mathrm{~m}$ test; 2. Speed endurance with the "Run $60 \mathrm{~m}$ " test; 3 . Running speed and mobility to move in a horizontal plane with the Running Shuttle $10 \times 5 \mathrm{~m}$ test; 4 . Agility with the "Running Fast" test; 5. Explosive lower limb strength with the "Long Jump from Place" test; and 6. Strength endurance of the abdominal musculature with the "Back Squat-Sit" (Abdominal Crunches) Test. In the process of conducting physical education and sports classes, the specialized impact methodology is applied, the content of which includes combinations of physical and psychophysical means and methods of impact. The obtained results are processed by variational and comparative analysis. 


\section{Results}

The methodology was implemented with the active participation of the students. The pedagogical experiment was conducted for one academic year. The results of the tests conducted at the beginning of the study on the young people of the experimental and control groups reflect the state of their physical readiness.

The main indicators of the measured physical qualities for the two groups, calculated by analysis of variance, are presented: the minimum and maximum value of the respective indicator (Xmin, Xmax), the mean value of the indicator (Xsp), standard deviation $(\mathrm{S})$, coefficient of variation ( $\mathrm{V} \%$ ), coefficients of asymmetry (As) and excess (Ex). The reliability $(\mathrm{P} \%)$ between the mean values of the indicators in the experimental and control groups was calculated. In analyzing the results of the study, the physical fitness status of the youths in the control group who participated in regular physical education and sports classes was also determined. The methodology was applied on the youths of the experimental group for two semesters in the process of conducting regular classes in physical education and sports.

When summarizing the changes that occurred in the physical qualities that make up the physical readiness of the young people in the experimental group, a positive impact of the applied methodology is demonstrated (Table.1).

The Increased values of the indicators of the studied physical qualities are reliable data, which is an indicator of the increase in the degree of physical readiness of youth for action in various extreme situations. Greater positive changes of the youths of the experimental group occurred in explosive strength of the lower limbs $(\mathrm{P}=99 \%)$ and strength endurance of the abdominal muscles $(\mathrm{P}=99 \%)$, and smaller changes in speed $(\mathrm{P}=96 \%)$ and agility $(\mathrm{P}=95 \%)$.

Table 1. Changes of the physical readiness of the young people of the experimental group before and after the experiment

\begin{tabular}{|c|l|c|c|c|c|c|c|c|}
\hline \multirow{2}{*}{ № } & Indicators & \multicolumn{2}{|c|}{ Before } & \multicolumn{2}{|c|}{ After } & \multirow{2}{*}{ d } & \multirow{2}{*}{ d \% } & \multirow{2}{*}{ P \% } \\
\cline { 2 - 6 } & Test & $\overline{\mathbf{x}} \mathbf{1}$ & $\mathbf{S 1}$ & $\overline{\mathbf{x}} \mathbf{2}$ & $\mathbf{S 2}$ & & & \\
\hline $\mathbf{1}$ & Run $\mathbf{3 0} \mathbf{~ m}$ & 5.3 & 0.36 & 5.0 & 0.32 & 0.3 & 6.0 & 96 \\
\hline $\mathbf{2}$ & Run $\mathbf{6 0} \mathbf{~ m}$ & 9.0 & 0.63 & 8.8 & 0.43 & 0.2 & 2.2 & 95 \\
\hline $\mathbf{3}$ & Shuttle run 10x5m & 19.0 & 1.35 & 18.6 & 0.92 & 0.4 & 2.1 & 97 \\
\hline $\mathbf{4}$ & Quick test & 7.8 & 1.64 & 7.5 & 1.55 & 0.3 & 3.9 & 95 \\
\hline $\mathbf{5}$ & Long jump & 216 & 1.44 & 240 & 24.31 & 24 & 11 & 99 \\
\hline \multirow{6}{6}{} & Crunches & 23.3 & 4.74 & 26.3 & 3.0 & 3.0 & 13 & 99 \\
\hline
\end{tabular}

At the beginning of the experiment, the young men in the experimental group jumped $216 \mathrm{~cm}$. At the end of the experiment they jumped $240 \mathrm{~cm}$. i.e. $24 \mathrm{~cm}$. more compared to the beginning of the experiment at $\mathrm{P}=99 \%$. The improvement in the 
explosive power of the lower limbs of the youngsters was the result of the applied methodology, which also positively influenced the speed-strength endurance of the abdominal muscles ( $\mathrm{P}=99 \%)$.

The methodology influenced slightly less the speed endurance and speed capabilities and horizontal plane locomotion. The decrease in agility, as highlighted, was due to the more precise execution of the defined movements. Therefore, the formed physical readiness of the youngsters of the experimental group for action in extreme situations, as a result of the applied methodology, is of a higher degree, compared to their physical readiness at the beginning of the experiment, when this methodology was not applied. The newly formed physical readiness of the youngsters was related to overcoming greater difficulties requiring greater and longer efforts of the abdominal and lower limb muscles.

There was no significant change in the physical readiness to act in difficult situations in the control group (Table 2). In the process of regular physical education and sports classes, their physical qualities improved very little. The increased values of the physical qualities indicators were very small and unreliable, indicating that the physical readiness of the youths in the control group, to which the impact methodology was not applied, did not change significantly. There are some tendencies for its degree to increase due to the improvement of speed and speed-strength endurance of the abdominal muscles. Of all the indicators of the studied physical qualities, building the readiness to react in extreme situations in the youths of the control group, only agility changed significantly $(\mathrm{P}=96 \%)$. However, this change was negative. Agility decreased by $8.2 \%$ in the control group youths during the experimental period. The most probable reason for the decrease in agility was the limited application of the more complex combinations of exercises in the process of conducting physical education and sports classes. Therefore, it is necessary to enrich the content of training classes with reliable specialized physical and psychophysical means and methods of influence.

Table 2 presents the results of the study of the physical qualities that make up the physical readiness of the young people in the control group before and after the experiment, where no significant changes occurred.

Table 2. Changes of the physical readiness of the youth of the control group before and after the experiment

\begin{tabular}{|c|l|c|c|c|c|c|c|c|}
\hline \multirow{2}{*}{ № } & Indicators & \multicolumn{2}{|c|}{ Before } & \multicolumn{2}{c|}{ After } & \multirow{2}{*}{ d } & \multirow{2}{*}{ d \% } & \multirow{2}{*}{ P \% } \\
\cline { 2 - 6 } & Test & $\overline{\mathbf{X}} \mathbf{1}$ & $\mathbf{S 1}$ & $\overline{\mathbf{X}} \mathbf{2}$ & $\mathbf{S 2}$ & & & \\
\hline $\mathbf{1}$ & Run $\mathbf{3 0} \mathbf{~ m}$ & 5,46 & 0.40 & 5.3 & 0.38 & 0.16 & 2.9 & 75 \\
\hline $\mathbf{2}$ & Run $\mathbf{6 0} \mathbf{~ m . ~}$ & 9.3 & 0.71 & 9.1 & 0,48 & 0.2 & 2.2 & 86 \\
\hline $\mathbf{3}$ & Shuttle run $\mathbf{1 0 x} \mathbf{5 m}$ & 18.6 & 1.17 & 18.1 & 0,98 & 0.5 & 2.7 & 85 \\
\hline $\mathbf{4}$ & Quick test & 7.3 & 1.68 & 6.7 & 1,65 & 0.6 & 8.2 & 96 \\
\hline
\end{tabular}




\begin{tabular}{|l|l|c|c|c|c|c|c|c|}
\hline $\mathbf{5}$ & Long jump & 213 & 16.27 & 214 & 21,18 & 1.0 & 0.5 & 38 \\
\hline $\mathbf{6}$ & Crunches & 22.5 & 4.17 & 23.4 & 3.4 & 0.9 & 4.0 & 67 \\
\hline
\end{tabular}

The effectiveness of the applied methodology of influence is due to the combination of physical and psychophysical means and methods of influence. In the practice of conducting physical education and sport classes very limited in most cases unconsciously applied separate means of psychophysical impact. Still not enough attention is paid to the great possibilities of these means and methods of influence. In a general view and in the practice of high sportsmanship also psychophysical influences are applied by coaches quite limitedly. It should definitely be emphasized that there are great possibilities for the application of psychophysical influences in physical education classes and in sports training.

One of the major barriers to overcoming the various hazards and difficulties of different extreme situations is the lack of awareness by the majority of today's youth of the vital benefits of physical fitness. It is in the process of overcoming various hazards and difficulties that adequate physical preparedness is formed.

Physical movement is the basis of human existence. One of the global factors affecting human health and development very negatively is limited physical movement. The other negative factor is limited mental movement, which appears as a barrier to the development of thinking. With limited thinking, a person would find it very difficult to cope with the emerging problems. The effectiveness of overcoming the various dangers and difficulties of the situations is greater when forming adequate psychophysical readiness in the youth on the way of their development and growth as highly qualified professionals.

When summarising the information from the experimental study processed by variance analysis, the effectiveness of the applied methodology is confirmed. Despite the limited difficult conditions in conducting the study, certain regularities in the development of physical qualities were found as a result of the application of the impact methodology in physical education classes.

In summarizing the variational and comparative analysis of the results of the study, it was found that the applied methods of influence in the process of conducting regular classes of students of physical education and sports has positively affected the physical readiness of young people in the experimental group. Physical education and sports classes had little impact on the physical readiness of the youths of the control group. It was not significant or reliable data. The effectiveness of the applied methodology is proved by the high probability of guarantee $(\mathrm{P} \%)$ of differences between the mean values of the studied physical qualities after the experiment (Table.3). As can be seen from the table, the methodology had a stronger effect on speed (30 m run), speed-strength endurance of abdominal muscles (abdominal crunches) and on agility (Burpee test). These physical qualities are essential for the formation of physical preparedness for survival in extreme situations. 
Table 3. Changes of the physical readiness of the young people of the experimental and control group after the experiment

\begin{tabular}{|c|c|c|c|c|c|c|c|c|c|c|}
\hline \multirow{2}{*}{ № } & \multirow{2}{*}{$\begin{array}{l}\text { Groups studied } \\
\text { Test }\end{array}$} & \multicolumn{3}{|c|}{ Experimental } & \multicolumn{3}{|c|}{ Control } & \multirow{2}{*}{ d } & \multirow{2}{*}{ d \% } & \multirow{2}{*}{ P \% } \\
\hline & & $\overline{\mathbf{x}} 1$ & s1 & V\% & $\overline{\mathrm{X}} 2$ & S2 & V\% & & & \\
\hline 1 & Run $30 \mathrm{~m}$ & 5.0 & 0.32 & 6.0 & 5.3 & 0.38 & 7.6 & 0.7 & 14 & 99 \\
\hline 2 & Run $60 \mathrm{~m}$. & 8.8 & 0.43 & 4,9 & 9.1 & 0.46 & 5.1 & 0.30 & 3.4 & 99 \\
\hline 3 & Shuttle run $10 \times 5 \mathrm{~m}$ & 18.6 & 0.92 & 5.0 & 18.1 & 0.98 & 5.3 & 0.5 & 2.7 & 97 \\
\hline 4 & Quick test & 7.5 & 1.55 & 20.70 & 6.7 & 1.65 & 24.6 & 0.8 & 11 & 96 \\
\hline 5 & Long jump & 240 & 24.31 & 10.11 & 214 & 21.18 & 9.9 & 26 & 3.9 & 97 \\
\hline 6 & Crunches & 26.3 & 3.0 & 11.4 & 23.4 & 3.4 & 14.5 & 2.9 & 11 & 99 \\
\hline
\end{tabular}

\section{Conclusion}

Specialized impact methodology was applied to the students of the experimental group in the process of studying physical education and sports during one academic year. After statistical processing of the obtained results of the study, it was found that it positively influenced the measured physical qualities in the students of the experimental group. Adequate physical readiness for survival in extreme situations is then formed. It could be concluded that the applied impact methodology was effective and reliable.

\section{REFERENCES}

Alexiev, R., 2004. Survival in disaster situations. Sofia: NSA PRESS [in Bulgarian]

Geshev, P., 2014. Theory and methodology of survival in extreme situations. Sofia: Bolid ins [in Bulgarian]

Kaikov, D., 1988. Theory and methodology of research of extreme situations. Sofia: Military publishing [in Bulgarian]

Kaykov, D., 2014. Readiness for survival in extreme situations. Sofia: NSA PRESS [in Bulgarian]

Madansky, V., 2013. Survival in extreme conditions of military-professional activity. V. Tarnovo: NVU "Vasil Levski" [in Bulgarian]

Marinov, T., 2015. Formation of adequate readiness in students for survival in crisis situations. Sofia: NSA PRESS [in Bulgarian]

Stavreva, I., 2015. Opportunities for adaptation of students' physical training to the requirements of professional activity in the mining industry. Yearbook of the Mining and Geological University "Sv. Ivan Rilski" Sofia, IV - Humanities and Economic Sciences. 58(4)

Stoycheva, V., 2019. Specialized physical training of youth for survival in extreme situations. Sofia: NSA PRESS [in Bulgarian] 
Stoycheva, V. \& Kaykov, D., 2018. Formation of physical readiness in young people for action in difficult situations. Sofia: NSA PRESS [in Bulgarian]

$\square$ Vesela Stoycheva https://orcid.org/0000-0003-2252-4465 University of Architecture Civil Engineering and Geodesy 1, Hr. Smirnenski Blvd. Sofia, Bulgaria E-mail: vesela.stoicheva@abv.bg 